\title{
Development of multi-value circulation based on remanufacturing
}

\author{
Kenichi Nakajima ${ }^{1, *}$, Mitsutaka Matsumoto ${ }^{2}$, Hideyuki Murakami ${ }^{3,4}$, Masao Hayakawa ${ }^{3}$, Yasunari Matsuno ${ }^{5}$, \\ and Wataru Takayanagi ${ }^{1}$ \\ ${ }^{1}$ Center for Material Cycles and Waste Management Research, National Institute for Environmental Studies, 16-2 Onogawa, \\ Tsukuba, Ibaraki, 305-8506, Japan \\ 2 Advanced Manufacturing Research Institute, National Institute of Advanced Industrial Science and Technology, 1-2 Namiki, \\ Tsukuba, Ibaraki, 305-8564, Japan \\ ${ }^{3}$ Research Center for Structural Materials, National Institute for Materials Science, 1-2-1 Sengen, Tsukuba, Ibaraki, 305-0047, \\ Japan \\ 4 Department of Nanoscience and Nanoengineering, Graduate School of Advanced Science and Engineering, Waseda University, \\ 3-4-1, Okubo, Shinjuku-ku, 169-8555, Japan \\ ${ }^{5}$ Department of Urban Environment Systems, Chiba University, 1-33, Yayoicho, Inage Ward, Chiba-shi, Chiba, 263-8522, Japan
}

Received: 21 June 2018 / Accepted: 26 October 2018

\begin{abstract}
Remanufacturing is an industrial process that turns used products into new ones with the same quality, functionality, and warranty as new products; it is a critical element for realizing a resource-efficient manufacturing industry and a circular economy. Remanufacturing may involve adding new and better functionality to used products, such as adding more wear-resistant materials to the surface or new sensor systems. Remanufacturing has been undertaken for products such as: automobile parts, machinery, photocopiers, single-use cameras, furniture, and turbine components, etc. It is generally superior to material recycling in terms of energy and material savings. Our project aims to develop technologies necessary for the promotion of remanufacturing and to establish a cooperative network related to remanufacturing. As technical development items, our aim is to develop methods to assess the reliability of parts/components, develop technologies to restore deteriorated metal surfaces of used products, introduce production management methods for remanufacturing, and design a circulation system to retain the added values of products. In this paper, we introduce an outline of the project and present some preliminary results. This paper shows the possibility to quantitatively evaluate the carbide distribution (size and density) of the carburized surface of a gear, and also shows the potential to repair materials exposed to a hightemperature oxidative atmosphere by Pr-Ir coating technology.
\end{abstract}

Keywords: remanufacturing / recycle / circular economy / closing the loop / surface repair / reliability assessment

Résumé. Conception de la circulation à valeurs multiples basée sur le reconditionnement. Le reconditionnement est un processus industriel qui transforme les produits usagés en nouveaux produits avec la même qualité, la même fonctionnalité et la même garantie que les nouveaux produits. C'est un élément essentiel pour la mise en place d'une industrie manufacturière utilisant efficacement les ressources et d'une économie circulaire. Le reconditionnement peut impliquer l'ajout de fonctionnalités nouvelles et améliorées aux produits utilisés, tels que l'ajout de matériaux plus résistants à l'usure à la surface ou de nouveaux systèmes de capteurs. Le reconditionnement a été entrepris pour des produits tels que: des pièces automobiles, des machines, des photocopieurs, des caméras à usage unique, des meubles, des composants de turbines, etc. Il est généralement supérieur au recyclage de matériaux en matière d'économies d'énergie. Notre projet vise à développer les technologies nécessaires à la promotion de la refabrication et à établir un réseau de coopération lié à la refabrication. En tant qu'éléments de développement technique, notre objectif est de développer des méthodes pour évaluer la fiabilité des pièces/composants, développer des technologies pour restaurer les surfaces métalliques détériorées des produits usagés, introduire des méthodes de gestion de la production pour le réusinage et concevoir un système de circulation pour conserver les valeurs ajoutées des produits. Dans cet

\footnotetext{
* e-mail: nakajima.kenichi@nies.go.jp
} 
article, nous présentons les grandes lignes du projet et quelques résultats préliminaires. Cet article montre la possibilité d'évaluer quantitativement la distribution de carbure (taille et densité) de la surface cémentée d'un engrenage, ainsi que le potentiel de réparation des matériaux exposés à une atmosphère oxydante à haute température grâce à la technologie de revêtement Pr-Ir.

Mots clés : reconditionnement / recyclage / économie circulaire / boucler la boucle / réparation de surface / évaluation de fiabilité

\section{Introduction}

A rapid rise in the use of natural resources has been associated with both economic growth in emerging countries and technological innovation in industrialized countries. UNEP's International Resource Panel (UNEP IRP) has pointed out the importance of decoupling resource use and the negative environmental impacts associated with economic activity [1]. The aim of a circular economy is to provide a better alternative to the current linear economy, which is based on the "take, make, and discard" extractive industrial model. In the linear model, value is added by extracting resources from the earth, refining them for manufacturing, assembling them into products, and distributing them to consumers. After the consumer uses a product, however, its value plummets [2]. Remanufacturing is an industrial process that turns used products into ones with the same quality, functionality, and warranty as new products; it is a critical element of the circular economy to improve resource efficiency [3] and to retain the added value of products for as long as possible [2].

Remanufacturing can involve adding new and better functionality to used products [6], which has been undertaken for products such as automobile parts, machinery, photocopiers, single-use cameras, furniture, turbine components, etc. Research has shown that remanufacturing saves up to $85 \%$ of virgin materials as compared with manufacturing new products [4]; furthermore, original production processes can use as much as six times the energy as compared to remanufacturing processes for the same products [5]. In addition to the environmental benefits, remanufacturing is expected to create highly skilled jobs and economic growth. The United States and Europe currently have the largest remanufacturing markets, and also other countries (e.g. Singapore, People's Republic of China, etc.) have been rapidly developing their own remanufacturing industries. The production value of remanufactured goods in the United States was 43 billion dollars in 2011, with the production of remanufactured aerospace products, heavyduty and off-road (HDOR) equipment, and motor vehicle parts accounting for $63 \%$ of the U.S. total. Even so, the remanufacturing intensity, which is defined as the ratio of the value of production shipments of remanufactured goods to total sales of all products within a given industry sector, was less than $2 \%$ in the United States in the same period [6].

Technological developments in remanufacturing processes, which consist of disassembling, cleaning, inspecting, repairing, replacing, and reassembling the components of a product, are necessary for the promotion of remanufacturing, but inspecting and repairing products are also necessary elements to improve resource efficiency and the reliability of remanufactured products. To develop the technologies necessary to promote remanufacturing and to establish a cooperative network related to remanufacturing, our research team launched the "Development of MultiValue Circulation Based on Remanufacturing" project supported by the Japan Science and Technology Agency (JST). JST launched the research program, "Innovation in Manufacturing Processes for Sustainable Resource Circulation" in the research area of "Realization of a Sustainable Society" as part of its Mirai Program in 2017. Our project was accepted from among more than 100 applications from around Japan. In this paper, we present an outline of the project and some preliminary results.

\section{Project overview}

An overview of the project is presented in Figure 1. As technical development items, our aim is to develop methods to assess the reliability of parts/components, develop technologies to restore deteriorated metal surfaces of used products, introduce production management methods for remanufacturing, and design a circulation system to retain the added values of products. We focus on above mentioned aerospace products, HDOR equipment, and motor vehicle parts with large remanufacturing market.

For the research in inspection, the project focuses on the reliability assessment of friction parts. Gears and other friction parts, which transmit the driving force, are essential parts of machines and of the social infrastructure of modern society. These parts are worn by contact friction with other objects, and the reliability of used parts influences their use in a circular system. We are also focusing on surface repair technologies for metallic components used at elevated temperatures and are trying to apply these methods to recoat materials and partially repair damaged parts. We currently carry out these development items independently by collaborating with different companies. But, we selected these items because these are presumably common research items that are significant to promote remanufacturing. The situations of the development are presented in the following sections.

\section{Preliminaly results and discussion}

\subsection{Production management methods for remanufacturing}

Remanufacturing makes use of used products taken back from consumers. This feature makes production management complex, sometimes more so than management of traditional new product manufacturing because of uncertainties in timing, quantity, and quality of returned products [7] and more operational variability [8]. There- 


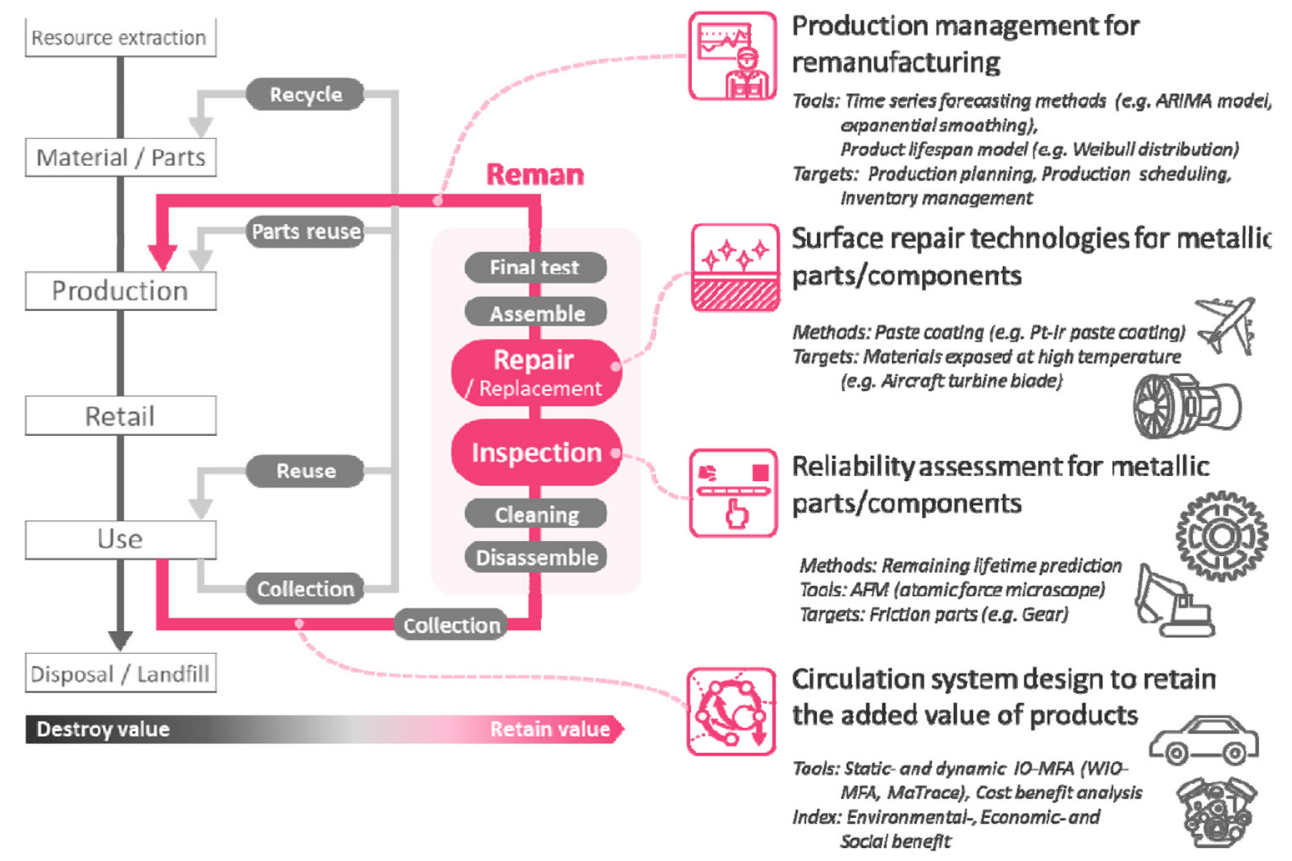

Fig. 1. Overview of the "Development of multi-value circulation based on remanufacturing" project.

Fig. 1. Aperçu du projet «Développement de la circulation à valeurs multiples basé sur le reconditionnement ».

fore, developing an effective production management scheme in remanufacturing is an important challenge in enhancing the productivity of remanufacturing processes.

Developing a reliable forecasting process is also a critical step to reduce the complexity of the overall remanufacturing process. Two approaches have been taken to develop methods of predicting product returns and the demand for remanufactured products. One is to develop a model assuming that the time distribution of new product sales is known, while the other assumes that it is not known. The former is reasonable when the original manufacturers conduct the remanufacturing, whereas the latter is better when independent remanufacturers do it. An example of a known time distribution is presented in Toktay et al. [9], who developed a model to predict product returns of Kodak single-use cameras. Their model used information on the timing of new product sales and was based on a discretetime distributed-lag model. Matsumoto and Komatsu [10] presented an examination of the precision of forecasts of the timing of demand of remanufactured auto parts in which the availability of data on the timing of new products sales was not assumed. In our current study of remanufacturing of automotive parts, we have collaborated with independent remanufacturers who do not generally possess data on new product sales. Therefore, we developed a model that does not use such information and examined the accuracy of the forecasted sales.

The project aims to develop a method to forecast the number of orders of remanufactured products. Figure $2 \mathrm{a}$ is an example of data from an auto parts remanufacturer showing the monthly sales for a specific type of remanufactured parts. The company's sales data for 120 different type parts over a period of 144 months (12 years) from January 2002 to December 2013 were collected. We applied a forecasting algorithm to the data and examined the accuracy of the forecast. From the data of 12 years, the data for the first 11 years were used to prepare forecasts for the last 1 year, and the accuracy was verified by comparing the forecast value and the actual value in the forecast term. In specific, we verified the accuracy by evaluating the cumulative average percentage error for 2 months because the demand forecast over 2 months in future is important for the company's production planning. We used the triple exponential smoothing forecasting method [11] as the forecasting algorithm. Figure $2 \mathrm{~b}$ shows the forecast by the algorithm and the actual data for the data shown in Figure 2a. The cumulative average percentage error for 2 months value for the forecast in Figure $2 \mathrm{~b}$ is $27.1 \%$. The evaluation was conducted for 120 different type parts, and the average of CAPE $(2)$ was $24.3 \%$.

Developing a reliable forecasting process would be a critical step for the optimization of the overall production management of remanufacturing processes. We are currently examining other models that are effective in increasing the forecast accuracy and examining methods to incorporate them into our analysis. Our next goal is to improve forecast accuracy by incorporating new and more effective methods.

\subsection{Reliability assessment methods for friction parts}

The surface layer of a metal gear, a typical friction part, is strengthened by carburization. The useful life of a gear ends when cracks form on the surface layer, and most gears currently are discarded without reuse even if cracks have not been confirmed. Because large gears have a high added value and are widely used, it would be useful to establish a remanufacturing technology based on a method utilizing 


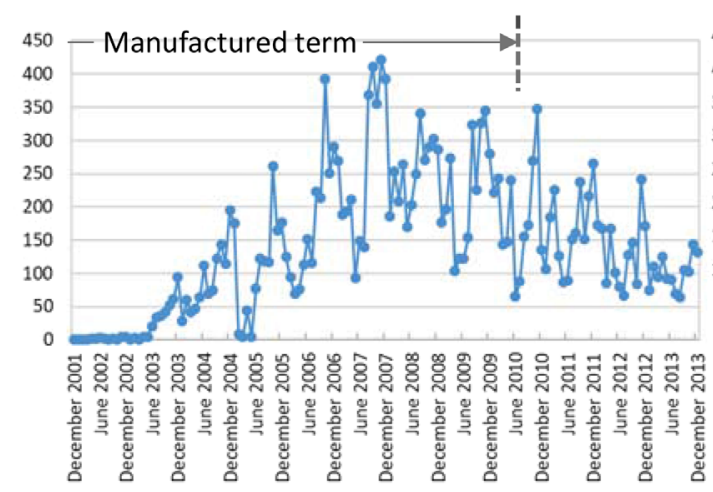

(a)

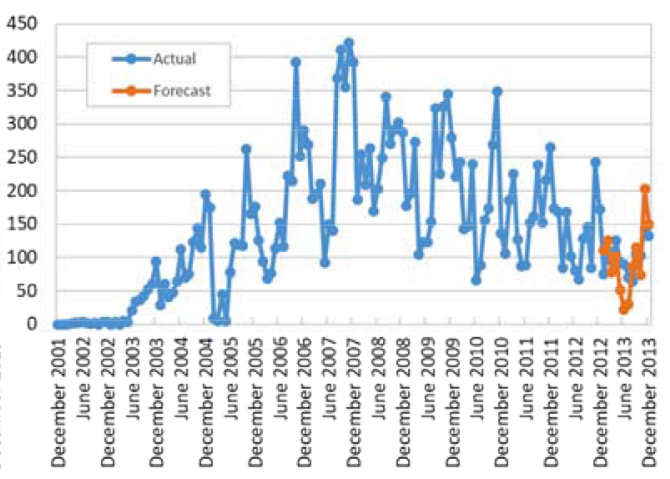

(b)

Fig. 2. Time series of the (a) sales of remanufactured auto parts, and (b) forecasted sales by the triple exponential smoothing method.

Fig. 2. Séries chronologiques des ventes (a) de pièces automobiles remises à neuf, et (b) des ventes prévues par le triple procédé de lissage exponentiel.

the predicted remaining lifetime. In this project, we are developing a prediction method based on the gear destruction mechanism.

Conventionally, the metal structure of the gear surface layer can be observed by using an optical microscope (OM) or scanning electron microscope (SEM), to observe formed surface step (unevenness) between carbide and martensitic matrix by chemical corrosion (etching), since the etching corrodes the martensitic matrix selectively, so carbide is left convexly. Up to $100 \mu \mathrm{m}$ of the gear surface layer is strengthened by carburization, and the surface metallic structure is different from the inner structure. Because the unevenness caused by etching on the surface layer is large relative to minute carbide particles, it is difficult to visualize carbide by conventional analysis methods.

It is possible, however, to visualize fine carbides by using an atomic force microscope (AFM) with high vertical resolution. Etching forms a step of $100 \mathrm{~nm}$, but by using special electrolytic polishing for surface treatment, the step between the carbide and the martensitic matrix can be reduced to $10 \mathrm{~nm}$ or less. Figure 3 shows AFM images of a typical low alloy carbon steel used for gears by etching and electropolishing. The contrast between black and white indicates the surface depth, with the white particles being convex portions that correspond to carbides. In the case of the etching surface, the carbide is unclear because of the influence of the surface unevenness of the martensitic matrix. The white carbide particles and their distribution along the grain boundaries are much easier to see with the electropolishing technique (Fig. 3b). The crystal phase of the martensitic matrix is also clear, indicating that a surface step is formed corresponding to the difference in crystal orientation $[12,13]$.

These results highlight the potential for a quantitative evaluation of the carbide distribution (size and density) of the carburized surface of a gear. In addition, we also established a microstructure observation technique to investigate carbide changes in the carburized surface and the relationship between micro cracks and carbide particles.
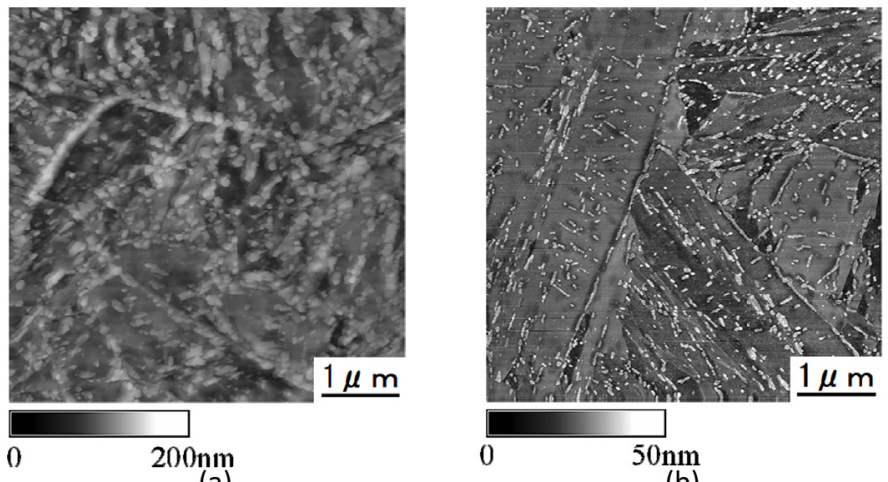

(a)

Fig. 3. Atomic force microscope images of low carbon alloy steel: (a) etching surface; (b) electropolishing surface [12].

Fig. 3. Image au microscope à force atomique en acier allié à faible teneur en carbone: (a) surface de gravure; (b) surface de polissage électrolytique [12].

\subsection{Surface repair technologies for metallic components used at elevated temperatures}

Structural materials inevitably are damaged after longterm use. For example, materials exposed to a hightemperature oxidative atmosphere will experience oxidation, hot corrosion, and high-temperature erosion. Surface modifications are a potential solution to these types of problems, and protective coatings against oxidation and hot corrosion could extend components' lives by retarding material deterioration. Protection can be obtained by the formation of a thermodynamically stable oxide scale such as $\mathrm{Al}_{2} \mathrm{O}_{3}, \mathrm{Cr}_{2} \mathrm{O}_{3}$, or $\mathrm{SiO}_{2}$. Of these, $\mathrm{Al}_{2} \mathrm{O}_{3}$ has been reported to offer the most protection when the components are used above $1000^{\circ} \mathrm{C}$ [14]. Therefore, materials used for turbine components in the hottest section of gas turbines are usually coated with an Al-enriched layer on the surface. Aluminized and CoNiCrAlY overlay coatings are also typical examples of this technology. 


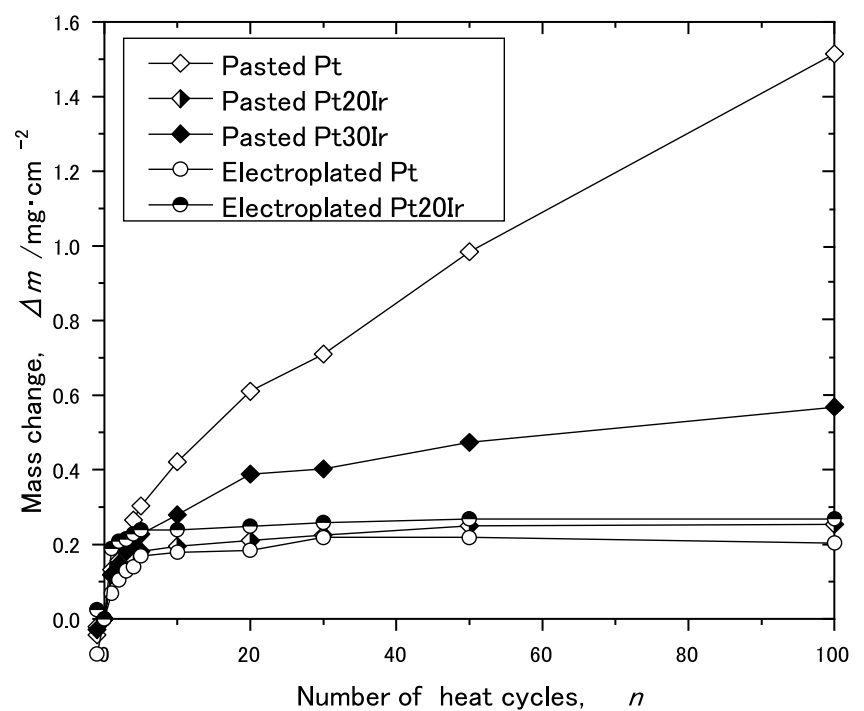

Fig. 4. Oxidation kinetic curve of the specimens during cyclic oxidation test at $1423 \mathrm{~K}$ [15].

Fig. 4. Courbe cinétique d'oxydation des échantillons lors du test d'oxydation cyclique à 1423 K [15].

Nevertheless, such coatings are not effective for very long periods for two reasons:

- when the oxide scale reaches a certain thickness, differences in the thermal expansion coefficients between the oxide surface and the underlying metallic materials lead to spallation and surface fracture;

- more importantly, interdiffusion between the substrateand the coated layer gives rise to the precipitation of detrimental phases (in the so-called secondary reaction zone), which weakens the mechanical properties of the substrates.

Therefore, optimization of coating materials and processes remains an ongoing issue for material scientists.

If one can find a coating process which leads to minimal damage of the substrate material, recoating of oxidation resistant materials would be possible, which may further extend the life of components. From this perspective, we propose the use of Pt-Ir paste (slurry) coatings, in which Pr-Ir nanoparticles are mixed with volatile liquid resin supported to form a paste (slurry) type and then coated on the surface of materials by the simple liquid spray method. This process has several advantages: the paste (slurry) coatings are easy to conduct, cause less damage to substrates, and offer comparable oxidation resistance. Figure 4 shows oxidation kinetic curves of pasted and electroplated coatings [15]. In the figure, mass gain is attributed to the formation of surface oxides, thus specimens with lower mass gain can be regarded to the better oxidation resistance. The figure indicates that a Pt-Ir paste coating has comparable oxidation resistance to Pt-electroplated coatings, which are already industrially applied. In addition, as shown in Figure 5, substrate damage is far less in the specimen coated with a PtIr paste than in the Pt electroplated specimen, the latter had void formations after an oxidation test. We are now trying to apply this method to recoat materials and to repair damaged parts [15].

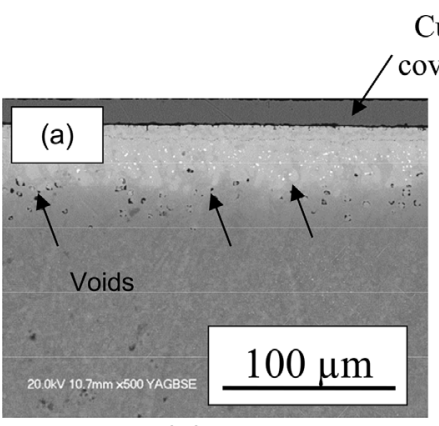

(a)
$\mathrm{Cu}$

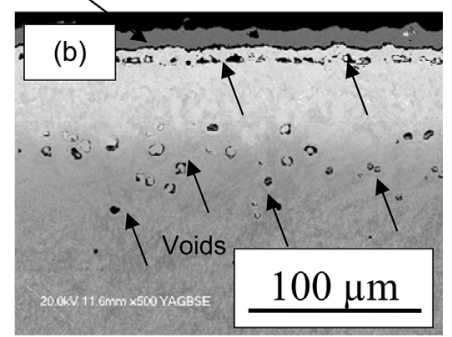

(b)
Fig. 5. Cross-sectional microstructure of coatings after 100 cyclic oxidation tests at $1423 \mathrm{~K}$ : (a)Pt-20Ir pasted; (b) Pt electroplated specimens [15].

Fig. 5. Microstructure en coupe transversale des revêtements après 100 tests d'oxydation cyclique à 1423 K: (a) Pt-20Ir collé; (b) spécimens électrodéposés au Pt [15].

\subsection{Circulation system designed to retain added value}

Global demand for metals has rapidly increased as the global economy has grown to create huge amounts of social material stocks $[16,17]$. Thinking in terms of a circular economy and "closing the loop" [18] would help to significantly reduce pressure on natural resources and lead a transition to a sustainable economic system that encompasses the concept of decoupling resource use and economic growth. In this situation, material recycling that can turn wastes into resources will play a key role in the transition from a linear economy to a circular economy. However, the material cycle loop has not closed, and materials are still being lost [19] as products end up in landfills or are incinerated, quickly destroying the value added in every step from extraction to retail. Remanufacturing, refurbishment, and repair and direct reuse (RRRDR) practices [20] to expand product's service life would play key roles in the transition. Remanufacturing could play a key role in improving resource efficiency and retaining the added value of existing products for as long as possible.

In this project, we are continuing to evaluate the design of the circulation system with the goal of closing the material cycle to retain the added value of products with a focus on the material circulation system of vehicles with huge primary material inputs in the manufacturing phase. We focus on auto parts with large shipment market in Japan. In recent years, the annual shipment value of auto parts in Japan has been approximately 19 trillion yen [21], whereas that of reused and rebuilt auto parts was quite small. Japanese Ministry of Economy, Trade and Industry estimated the total shipment value of reused and rebuilt auto parts was approximately 0.2 trillion yen in 2012 [22].

Figure 6 shows the shipment value of reused and rebuilt auto parts and the price reduction rate for new item price in Japan in 2017, which was estimated from commercial statistical data by Parts Station Net [23]. Parts Station Net is one of the largest reuse and rebuilt auto parts market in Japan. Reused auto parts refer component that are reused 


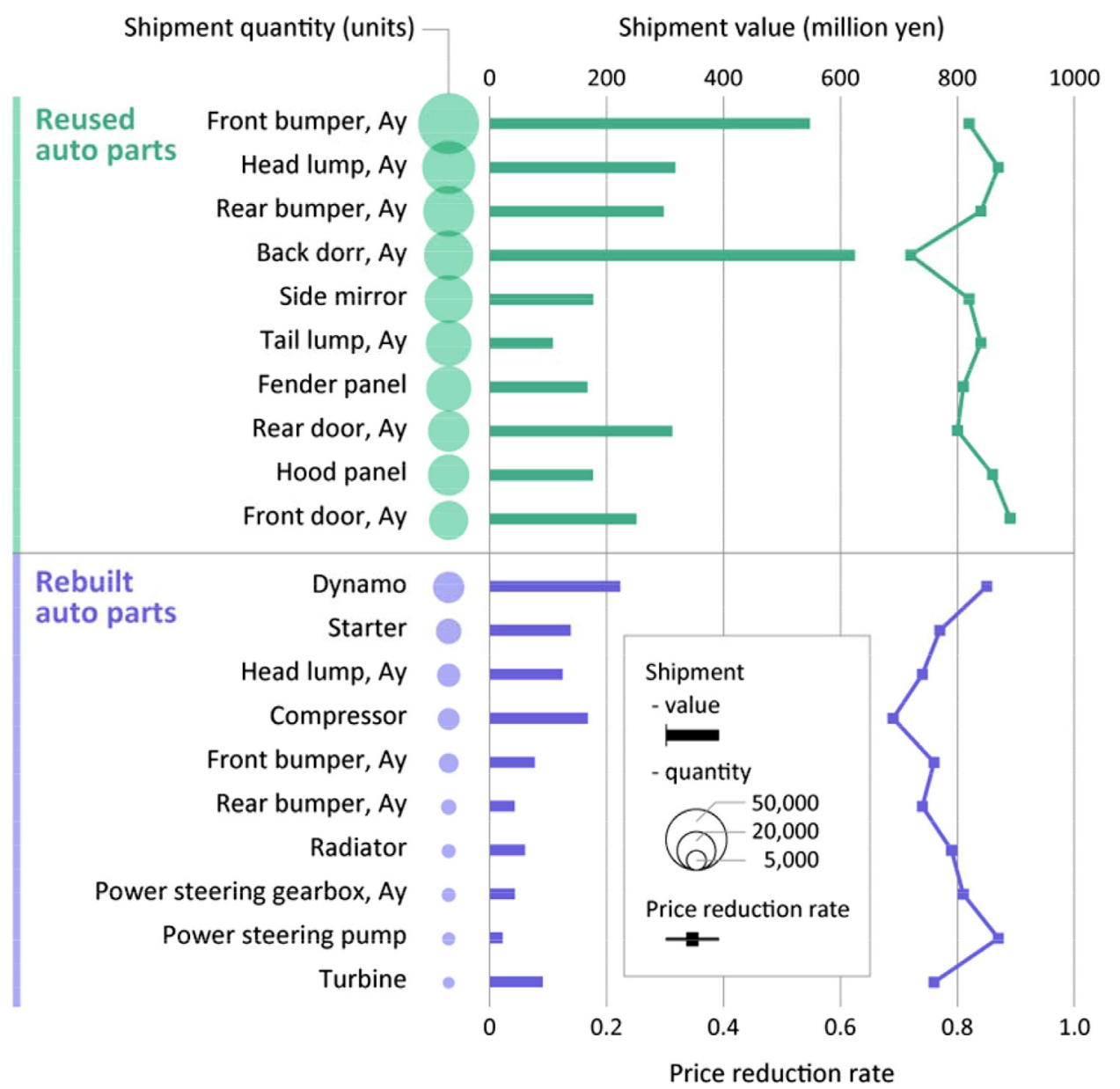

Fig. 6. Estimated shipment value of reused and rebuilt auto parts with the largest shipment quantity in Japan in 2017, Ay: assembled parts.

Fig. 6. Valeur estimée des expéditions de pièces automobiles réutilisées et reconstruites, avec la plus grande quantité d'expédition au Japon en 2017, Ay: pièces assemblées.

after removal from ELVs without replacement/repair of parts or with minor repair. Firms have registered whether it is a reused part or a rebuilt part by self-declaration. The total shipment value of reused ( 8.0 billion yen) and rebuilt ( 1.7 billion yen) auto parts in 2017 was equivalent to $0.06 \%$ of the annual shipment value of auto parts in Japan.

The total shipment value of the top 10 reused commodities with the largest shipment quantity (3.0 billion yen) accounted for $37 \%$ of the total value of reused auto parts, and the total shipment value of the top 10 rebuilt auto parts with the largest shipment quantity ( 1.0 billion yen) accounted for $58 \%$ of the total value of rebuilt auto parts (Fig. 6). Reused and rebuilt parts are less expensive to produce as compared with newly manufactured parts, which means that prices can be set at lower levels, which in turn benefits the consumer. Our results show that the prices of most reused and rebuilt auto parts were about $70 \%$ lower than prices of comparable new auto parts. This result also highlights that rebuilt auto parts tended to be traded at higher prices than reused auto parts: the price reduction rate of assembled front bumper (front bumper, Ay) for new items was $82 \%$ for reused auto parts and $74 \%$ for rebuilt auto parts; the price reduction rate of assembled head lump (head lump, Ay) for new items was $87 \%$ for reused auto parts and $76 \%$ for rebuilt auto parts.

We close this section by pointing to possible future direction for research. It is expected not only to provide cost benefits to consumers, reuse and rebuild are also expected to extend service life of products and reduce of natural resource consumption. In this project, we have also evaluated the resource conservation effects of auto-parts recovery by reuse, rebuilding, and remanufacturing as compared with material recycling from end-of-life (EoL) vehicles (ELVs). Although, metals can theoretically be infinitely recycled in a closed loop without any degradation in quality, metal recycling can result in quality and material losses $[24,25]$. Open-loop recycling is typical for metal scrap recovered from end-of-life (EoL) products because mixing of different metal species results in scrap quality that no longer matches that of the original materials. Nakamura et al. [26] presented the "MaTracealloy" model, which is a novel dynamic material flow analysis (MFA) approach. The model quantifies quality 
and material losses associated with metal recycling under explicit consideration of the economy-wide interindustry flow of inputs and outputs by means of a new hybrid input/ output (IO)-MFA approach. It tracks the fate of metals embodied in each product over multiple product life cycles and includes accumulation, discard, recycling, and compositional details at the level of both alloys and products. Nakamura et al. [26] modeled the flow of chromium ( $\mathrm{Cr}$ ) and nickel $(\mathrm{Ni})$ in the Japanese steel cycle and showed the significant effect of scrap sorting; more than $70 \%$ of the initial functionality of $\mathrm{Cr}$ and $\mathrm{Ni}$ could be retained over a period of 100 years, whereas under a poor level of sorting, this value plunged to less than $30 \%$. However, the effect of resource conservation by reuse, rebuild, and remanufacturing has not been discussed. In this project, we focused on automobile engines and their reuse, with the aim of quantifying the amount of dissipated steel and its alloying elements (nickel and chromium) from the engine recycling process, along with elaborating on their dissipation paths by using the Ma-Trace model [25]. Components of engine (compressor, turbine, etc.) and assembled engine are major shipment auto parts in the market for reused and rebuilt auto parts. Our preliminary results [27] showed that reuse had nearly the same effects as recycling on the reduction of material losses, but achieved the extension of product's service life. A detailed analysis would contribute to clarify not only the positive effects but also the limitations of remanufacturing of auto parts.

Acknowledgments. This research was supported by Japan Science and Technology Agency (JST-Mirai Program Grant Number JPMJMI17C3).

\section{References}

1. United Nations Environmental Programme, International Resource Panel (UNEP IRP), 2011, Decoupling natural resource use and environmental impacts from economic growth, available at http:/ / www.resourcepanel.org/reports/ decoupling-natural-resource-use-and-environmentalimpacts-economic-growth (last consulted on: 2018/28/03)

2. E. Achterberg, J. Hinfelaar, N. Bocken, Master circular business with the value hill, 2016, available at https://www. circle-economy.com/wp-content/uploads/2016/09/financewhite-paper-20160923.pdf (last consulted on 2018/08/03)

3. Ellen MacArthur Foundation, Towards the circular economy Vol. 1: an economic and business rationale for an accelerated transitione, Tech. Rep. 2012, available at https://www. ellenmacarthurfoundation.org/assets/downloads/publica tions/Ellen-MacArthur-Foundation-Towards-the-CircularEconomy-vol.1.pdf (last consulted on 2018/08/03)

4. N. Nasr, Reman for success, Ind. Eng. 42, 26 (2010)

5. N. Nasr, M. Thurston, Remanufacturing: a key enabler to sustainable product systems, Proc. of 13th CIRP International Conference on Life-Cycle Engineering, 2006, pp. 15-18

6. United States International Trade Commission, Remanufactured goods: an overview of the U.S. and global industries, markets, and trade, USITC Publication 4356, Washington, 2012, pp. XVII-XVIII

7. M. Matsumoto, S. Yang, K. Martinsen, Y. Kainuma, Trends and research challenges in remanufacturing, Int. J. Precis. Eng. Manuf.-Green Technol. 3, 129 (2016)
8. M. Ilgin, S. Gupta, Environmentally conscious manufacturing and product recovery (ECMPRO): a review of the state of the art, J. Environ. Manag. 91, 563 (2010)

9. L. Toktay, L. Wein, S. Zenios, Inventory management of remanufacturable products, Manag. Sci. 46, 1412 (2000)

10. M. Matsumoto, S. Komatsu, Demand forecasting for production planning in remanufacturing, Int. J. Adv. Manuf. Technol. 79, 161 (2015)

11. C.C. Holt, Forecasting trends and seasonal by exponentially weighted averages. Office of Naval Research Memorandum 1957, 52, Reprinted in: Holt C.C. Forecasting seasonals and trends by exponentially weighted moving averages, Int. J. Forecast. 20, 5 (2004)

12. M. Hayakawa, T. Hara, S. Matsuoka, K. Tsuzaki, Microstructural observation of tempered martensite in a mediumcarbon low-alloy steel by atomic force microscopy, J. Jpn. Inst. Met. 64, 460 (2000)

13. M. Hayakawa, S. Matsuoka, K. Tsuzaki, Observations of prior austenite grain boundaries and carbides in the same area of tempered martensite in medium-carbon steel by atomic force microscopy, J. Jpn. Inst. Met. 65, 741 (2001)

14. N. Birks, G.H. Meier, F.S. Petit. Introduction of the hightemperature oxidation of metals, Cambridge University Press, 2006

15. D.C. Tue, T-K. Tsao, H. Murakami, L.T.H. Lien, Microstructure and oxidation behavior of $\mathrm{Pt}$ and $\mathrm{Pt}$-Ir diffusion coatings on Ni-base single crystal superalloy, Mater. Trans. 2018, submitted.

16. K. Nakajima, I. Daigo, K. Nansai, K. Matsubae, W. Takayanagi, M. Tomita, Y. Matsuno. Global distribution of material consumption: nickel, copper, and iron, Resour. Conserv. Recycl. 133, 369 (2018a)

17. K. Nakajima, I. Daigo, K. Nansai, K. Matsubae, W. Takayanagi, M. Tomita, Y. Matsuno, Global distribution of material stocks: iron, copper, and nickel, Matériaux \& Techniques 105, 511 (2017)

18. European Commission, 2015, Communication from the commission to the european parliament, The Council, The European economic and social committee and the committee of the regions closing the loop-An EU action plan for the Circular Economy, available at https://eur-lex.europa.eu/ legal-content/EN/TXT/?uri=CELEX:52015DC0614 (last consulted on: 2018/4/10)

19. T.E. Graedel, J. Allwood, J-P. Birat, M. Buchert, C. Hagelüken, B.K. Reck, S.F. Sibley, G. Sonnemann, What do we know about metal recycling rates? J. Ind. Ecol. 15, 355 (2011)

20. European Commission, 2017, Promoting remanufacturing, refurbishment, repair, and direct reuse, available at http:// ec.europa.eu/environment/international_issues/pdf/ 7 8_february_2017/workshop_report_B_Brus sels_-7_8_02_2017.pdf (last consulted on: 2018/4/10)

21. Japan auto parts industries association (JAPIA), Survey of auto parts shipment, 2016, available at http://www.japia.or. jp/research/foword.html (last consulted on: 2018/28/03)

22. Ministry of Economy, Trade and Industry. Market survey report 2014 (in Japanaese), available at http://www.meti.go. jp/policy/mono_info_service/mono/automobile/automobi le_recycle/examination/pdf/kaitaichousa.pdf (last consulted on: 2018/4/10)

23. BroadLeaf Co., Ltd. Parts Station Net, available at https:// www.broadleaf.co.jp/products/auto/psrc/ 
24. K. Nakajima, O. Takeda, T. Miki, K. Matsubae, T. Nagasaka, Thermodynamic analysis for the controllability of elements in the recycling process of metals, Environ. Sci. Technol. 45, 4929 (2011)

25. S. Nakamura, Y. Kondo, S. Kagawa, K. Matsubae, K. Nakajima, T. Nagasaka. MaTrace: tracing the fate of materials over time and across products in open-loop recycling, Environ. Sci. Technol. 48, 7207 (2014)
26. S. Nakamura, Y. Kondo, K. Nakajima, H. Ohno, S. Pauliuk, Quantifying recycling and losses of $\mathrm{Cr}$ and $\mathrm{Ni}$ in steel throughout multiple life cycles using Ma-Trace-Alloy, Environ. Sci. Technol. 51, 9469 (2017)

27. Z. Zhang, K. Takeyama, H. Ohno, K. Matsubae, K. Nakajima, T. Nagasaka, An estimation of the amount of dissipated alloy elements in special steel from automobile recycling process. 12th International Conference on Society \& Materials, 2018

Cite this article as: Kenichi Nakajima, Mitsutaka Matsumoto, Hideyuki Murakami, Masao Hayakawa, Yasunari Matsuno, Wataru Takayanagi, Development of multi-value circulation based on remanufacturing, Matériaux \& Techniques 107, 103 (2019) 